\title{
Editorial
}

\section{Considerations on the ICD-11 Classification of Psychotic Depression}

\author{
Søren Dinesen Østergaard ${ }^{\mathrm{a}}$ Anthony J. Rothschild ${ }^{\mathrm{d}}$ Peter Uggerby ${ }^{\mathrm{a}}$ \\ Povl Munk-Jørgensen ${ }^{\mathrm{a}}$ Per Bech $^{\mathrm{b}}$ Ole Mors ${ }^{\mathrm{c}}$ \\ a Unit for Psychiatric Research, Aalborg Psychiatric Hospital, Aarhus University Hospital, Aalborg, \\ ${ }^{b}$ Psychiatric Research Unit, Psychiatric Center Nordsjælland, Hillerød, and ${ }^{~}$ Centre for Psychiatric Research, \\ Aarhus University Hospital, Risskov, Denmark; ${ }^{d}$ University of Massachusetts Medical School and UMass \\ Memorial Health Care, Worcester, Mass., USA
}

\section{Introduction}

Depression accompanied by psychotic symptoms is referred to as delusional or psychotic depression (PD). PD is classified as a subtype of severe unipolar depression/ severe depression in bipolar disorder in the two current major diagnostic systems, namely the 10th revision of the International Classification of Disease (ICD-10) [1] and the 4th edition of the Diagnostic and Statistical Manual of Mental Disorders (DSM-IV) [2]. PD is prevalent [3, 4], underdiagnosed [5], undertreated [6] and has a high morbidity and mortality [7-9], but has received disproportionally little attention compared with other less prevalent and less severe mental disorders [10].

Based on the detection of a number of biological, clinical, therapeutic and prognostic differences between PD and non-psychotic depression (non-PD), it was proposed that psychotic depression should be categorized as a distinct syndrome in the DSM-IV [11-15]. The arguments against classifying $\mathrm{PD}$ as distinct from non-PD were summarized in the DSM-IV Source Book [16] and, to our knowledge, have changed little since then. Based on this source, the DSM-IV Work Group on Mood Disorders concluded that the differences between PD and non-PD were too vague to merit a further distinction between the two entities than that defined by the DSM-III-R (psychosis designated by a qualifying decimal point under the severity code) [17]. Therefore PD remained classified under severe depression in both the DSM-IV and the ICD-10.

During the DSM-IV/ICD-10 era a number of studies reporting significant differences between PD and nonPD have been published (for a review, see Rothschild [10]). Consequently, the discussion regarding the classification of PD goes on $[18,19]$ and is of the utmost importance at a time when the current diagnostic manuals are under revision $[20,21]$.

Below, we discuss the arguments in favour of and against classifying $\mathrm{PD}$ as a distinct syndrome under the affective disorders. In order to cover all aspects, the discussion will build upon the five criteria for the "valid psychiatric syndrome' as defined by Robins and Guze [22] - here accompanied by a sixth criterion covering 'treatment response'. Finally, based on this evaluation of the current evidence, we give an outline for a redefinition of $\mathrm{PD}$ for the upcoming 11th revision of the International Classification of Disease (ICD-11), which is due in 2015.

\section{KARGER}

Fax +4161306 1234

E-Mail karger@karger.ch

www.karger.com (c) 2012 S. Karger AG, Basel

$0033-3190 / 12 / 0813-0135 \$ 38.00 / 0$

Accessible online at:

www.karger.com/pps
Søren Dinesen Østergaard

Unit for Psychiatric Research, Aalborg Psychiatric Hospital

Aarhus University Hospital, Mølleparkvej 10

DK-9000 Aalborg (Denmark)

Tel. +45 2557 9050, E-Mail sdo@rn.dk 


\section{Clinical Description}

$\mathrm{PD}$ is characterized by the presence of delusions and/ or hallucinations in addition to depression. A typical case is a patient displaying anhedonia, psychomotor retardation, loss of interest, poor concentration and who is tormented by delusions of guilt, disease, worthlessness or impending disaster [10]. PD has a characteristic symptomatology which, apart from the psychotic features, involves a psychomotor disturbance (either agitation or retardation), rumination, insomnia [23, 24], cognitive dysfunction and perplexity more often than non-PD [15, 25-27]. A recent study has suggested that PD may also be accompanied by comorbid anxiety, somatoform and personality disorders more often than non-PD [28]. In recurrent depressive disorder a psychotic depressive episode often leads to subsequent psychotic episodes $[7,13]$ with similar delusional content $[11,29]$.

Regarding the course of disease, $\mathrm{PD}$ is associated with increased long-term psychosocial impairment [30, 31], increased rates of relapse [32] and higher levels of mortality compared to non-PD [9], possibly due to increased risk of suicide $[8,32,33]$.

One of the arguments raised by the DSM-IV Work Group on Mood Disorders against the classification of $\mathrm{PD}$ as a distinct entity was that the number of psychiatric syndromes was already too high [16]. This profusion of syndromes has recently been documented by a publication on the use of ICD-10 diagnoses of mental disorders in Danish hospital psychiatry [34]. This study reported that 380 diagnoses of mental disorders were available (using only 3-digit diagnostic codes, e.g. F20.0 for paranoid schizophrenia) and that the majority of these were used very rarely. The number of diagnostic syndromes should obviously be kept to a reasonable minimum, but since PD is a rather prevalent disorder $[3,4,10]$ and already defined in the diagnostic manuals, this argument seems misplaced in the discussion of defining PD as a distinct diagnostic syndrome.

Another counterpoint to PD being a distinct syndrome concerns the relationship between the severity of depression and the presence of psychosis. It has been suggested that the differences between PD and non-PD could reflect mere differences in depressive severity [16]. It also seems to be a common clinical assumption that psychosis is simply an indicator of the degree of severity in depression and that psychosis will eventually develop if a depression becomes sufficiently severe. This 'severity-psychosis' hypothesis is supported by some studies of PD $[35,36]$ and also underlies the current classification of PD in both the DSM-IV and the ICD-10, where the disorder only figures as a subtype of severe depression. However, recent findings call into question this theory. These studies have demonstrated that episodes of PD are not necessarily 'severe' according to the number of depressive symptoms $[25,37]$ and that patients without any history of psychosis may experience nonpsychotic depressive episodes of greater symptom severity compared to psychotic depressive episodes in patients with PD [38].

\section{Laboratory Studies}

One of the factors which kept the DSM-IV Work Group from separating PD from non-PD was that they considered the differences in biology between the two disorders to be too subtle [16]. During the DSM-IV/ICD10 era a number of 'biological' studies have been carried out and the existence of differences between patients with PD and non-PD are now widely accepted [10], although confounding due to comorbidity may also play a role [39]. The most consistent difference involves the regulation of the hypothalamic-pituitary-adrenal axis. Patients with depression have a dysregulated hypothalamic-pituitaryadrenal axis [40], but the dysfunction is significantly more pronounced in patients with PD compared to patients with non-PD and also compared to patients with schizophrenia. This has been demonstrated consistently through increased rates of non-suppression in the dexamethasone suppression test and high levels of blood and urinary free cortisol [41-43]. Importantly, the differences persist when adjusted for depression severity [44] and appear to be some of the most robust findings in the entire field of biological psychiatry. It has even been suggested by the American Psychiatric Association, that the dexamethasone suppression test may have a potential clinical utility in differentiating PD from other psychoses, i.e. schizo-affective disorder, bipolar disorder and schizophrenia $[45,46]$. In support of the pathophysiological role of the dysregulated hypothalamic-pituitary-adrenal axis in $\mathrm{PD}$, the glucocorticoid antagonist mifepristone has shown promise for the treatment of PD in some studies [47-49], but not others [50,51].

Patients with PD also have lower activity of the enzyme dopamine- $\beta$-hydroxylase than patients with nonPD $[52,53]$. Dopamine- $\beta$-hydroxylase converts dopamine to norepinephrine, and the lower activity could result in increased levels of dopamine which has been hypothesized to contribute to the risk of developing psychosis in PD as outlined in the 'corticosteroid/dopamine hypothesis for psychotic depression' [54]. 


\section{Delimitation from Other Disorders}

The delimitation of depression (and thereby also PD) from other mental disorders (most importantly schizoaffective disorder and schizophrenia) is defined in both the ICD-10 and the DSM-IV criteria and is supported by findings from both family [55] and follow-up studies [56]. The focus of this paper is mainly the distinction between $\mathrm{PD}$ and non-PD, which is covered in detail above and below.

\section{Follow-Up Studies}

Another counterpoint to PD being a distinct syndrome concerns the stability of the diagnosis [16]. A very recent study has caused reason to question the validity of PD due to its finding of low diagnostic stability over 10 years [57]. However, this study is affected by several limitations (a very young sample, a large proportion of males and changing diagnostic instruments over time) and the findings are in contrast to a number of studies reporting high diagnostic stability of PD $[3,56,58]$. Furthermore, changes in diagnoses over time and so-called diagnostic drift exists for all mental disorders $[59,60]$ and for virtually all diseases in general $[61,62]$.

\section{Family Studies}

According to Robins and Guze [22], familial transmission of mental disorders is a prerequisite for the definition of a valid psychiatric syndrome: 'Independent of the question of etiology, therefore, the finding of an increased prevalence of the same disorder among the close relatives of the original patients strongly indicates that one is dealing with a valid entity.' A recent populationbased family study has revealed that the familial transmission of mental disorders may be less specific than was previously assumed [63], i.e. having a parent with schizophrenia increases the offspring risk not only of schizophrenia and other psychotic disorders, but of all diagnoses across the spectrum of mental disorders. This finding illustrates that, if we accept a categorical diagnostic system, specific genetic transmission cannot be a rigid criterion.

Depression is heritable [64], but among the less heritable of the mental disorders, where schizophrenia and bipolar disorder lie at the other end of the spectrum [65]. However, studies have indicated that the heritability of $\mathrm{PD}$ is stronger than that of non-PD and that PD displays considerable specificity in familial transmission [55, 6671]. This is consistent with the theory which implies that PD represents a more biological/primary disorder compared to non-PD [19].

ICD-11 Classification of Psychotic Depression
Treatment Response

Another argument against the separation of PD from non-PD raised by the DSM-IV Work Group concerned the response to treatment: 'Still a number of questions can and should be raised about a separate designation ... particularly in regard to treatment, further prospective investigation is required' [16]. When this was written there was already a considerable body of literature showing that PD responded worse to both placebo and monotherapy with tricyclic antidepressants than did non-PD $[11,12,15,70,72-75]$. Since then only a few studies have compared the effects of psychopharmacological interventions in PD and non-PD. Two quite recent studies have not been able to confirm the previous differences in response, but should be interpreted within their limitations regarding external validity (study of an elderly population) [76] and lack of adjustment for baseline severity [77]. The general opinion remains that PD responds poorly to antidepressant monotherapy [10] and there is even some evidence suggesting that this regimen can exacerbate the psychotic dimension of the disorder [78, 79]. During the DSM-IV/ICD-10 era the treatment protocols comparing PD and non-PD have focused mainly on adjunctive psychotherapy and electroconvulsive therapy. The results of these studies indicate that PD responds poorly to psychotherapy $[80,81]$ but favorably to electroconvulsive therapy [82-84] compared to non-PD.

There is a growing body of evidence from recent randomized controlled trials, suggesting that the combination of an antidepressant and an antipsychotic is the superior pharmacological treatment approach in patients with PD [85-88]. In agreement with these findings, most major expert guidelines on PD recommend either electroconvulsive therapy or the combination of an antidepressant and an antipsychotic as first-line treatment [8991]. This recommendation differs significantly from those for non-PD, where the augmentation with antipsychotics is generally reserved for depression resistant to at least two trials with antidepressant monotherapy [89-91].

\section{Unipolar versus Bipolar Psychotic Depression}

The studies referenced above are mainly based on patients with unipolar psychotic depression (UPD). However, there is a close relationship between UPD and bipolar disorder [10]. Patients with UPD are at high risk of converting to bipolar disorder [92-95], relatives of patients with UPD have higher prevalence of bipolar disorder compared to relatives of patients with non-PD $[71,94$,

Psychother Psychosom 2012;81:135-144 
Fig. 1. Suggested ICD-11 definition of unipolar depression and bipolar disorder. The two figures outlined by a solid line define the actual diagnostic categories of bipolar disorder (corresponding to the current F31) and unipolar depression (corresponding to the current F32 and F33). The grey dotted line contains diagnoses that fall under the 'meta-syndrome' entitled PD. Each diagnosis is specified further depending on the presence of (1) hallucinations only, (2) delusions only or (3) hallucinations and delusions.

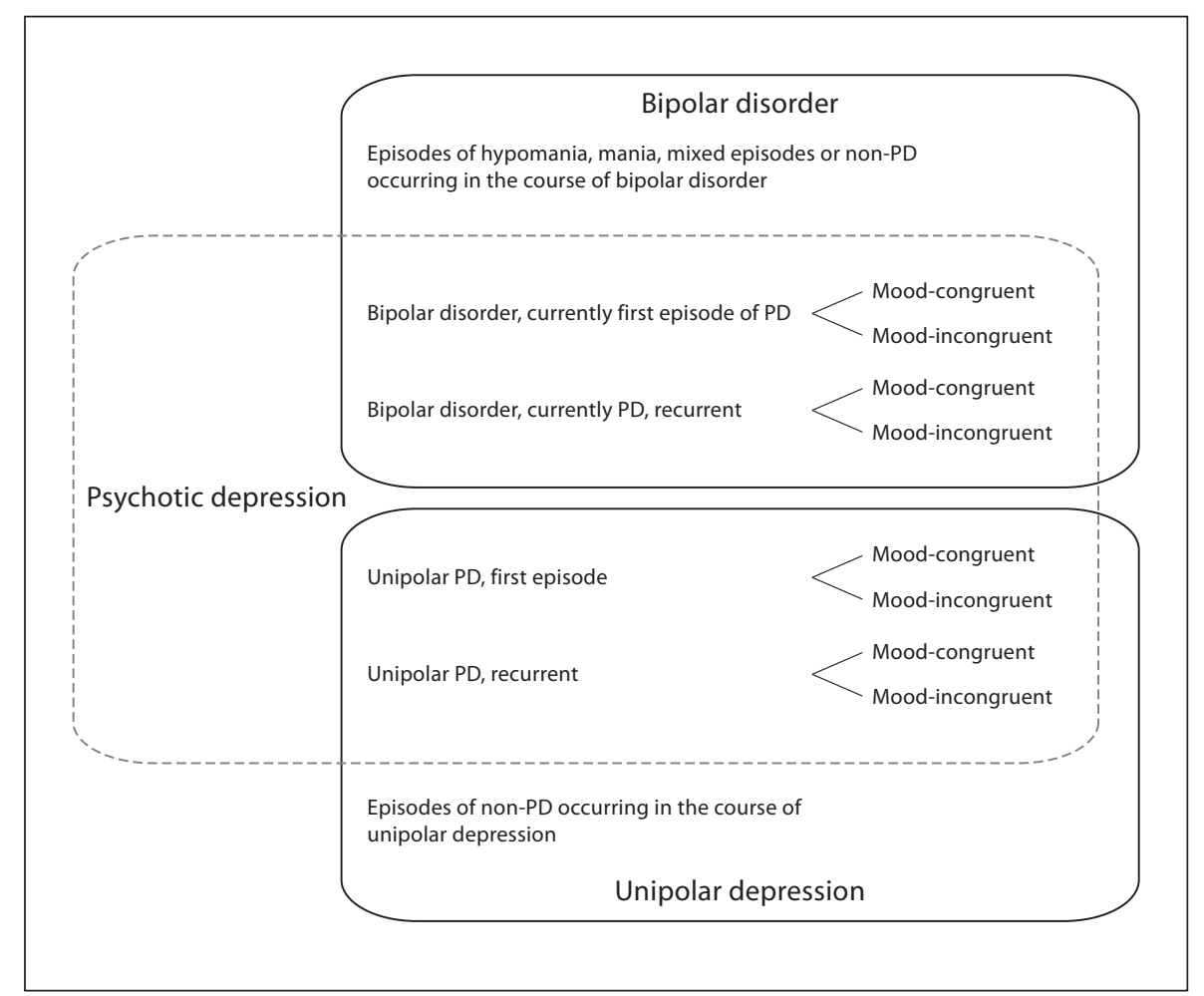

96], and unipolar depressed relatives of patients with bipolar disorders are more likely to suffer from the psychotic subtype than are unipolar depressed relatives of healthy controls [97]. A large number of studies have indicated that psychotic features are more prevalent in bipolar depression than in unipolar depression [98-101], but the literature published on the significance of psychosis in bipolar depression is somewhat sparse. However, equivalent to the case of UPD, it appears that the psychotic subtype of bipolar depression may also have implications for the symptomatology [102], treatment response [103], course of illness [104] and prognosis [105]. A study comparing patients with UPD and bipolar psychotic depression (BPD) did not detect any differences on a number of variables ranging from demographics to symptomatology [106]. Some studies of older date have suggested that patients with BPD may respond better than patients with UPD to the addition of lithium carbonate to the combination of an antidepressant and an antipsychotic $[107,108]$. In the ICD-10, BPD is classified as 'F31.5 - Bipolar affective disorder, current episode severe with psychotic symptoms'. Consequently, the 'severity issue' seems equivalent to that of the current definition of UPD.

\section{Discussion and Perspectives}

As outlined above, the number of studies reporting significant and clinically relevant differences between PD and non-PD has increased considerably over the past decades. This summary of the current evidence suggests that PD now fulfils the criteria for a valid psychiatric syndrome. The Task Force working with the classification of affective disorders in the upcoming 5th edition of the Diagnostic and Statistical Manual of Mental Disorders (DSM-V) has acknowledged this development in their proposed revision, where the label 'severe' has been removed from 'with psychotic features'. This means that PD will probably be classified at the same level as mild, moderate and severe depression without psychotic symptoms in the DSM-V [109]:

- 296.x1: mild depressive episode

- 296.x2: moderate depressive episode

- 296.x3: severe without psychotic features

- 296.x4: with psychotic features

where ' $x$ ' represents either ' 2 ' (single depressive episode) or ' 3 ' (recurrent depressive disorder).

Similarly, the severity criterion has been removed from the DSM-V criteria for BPD. We recommend that 
this initiative is followed in the upcoming ICD-11. Our suggestion for the ICD-11 classification of depression with psychotic symptoms is illustrated in figure 1. Note that the current distinction between unipolar and bipolar disorders is maintained. The suggested modification allows the definition of a useful 'meta-syndrome' entitled 'psychotic depression' across the affective disorder chapter. The PD syndrome is defined by the diagnoses contained by the grey dotted line. Below we list the suggested ICD-11 diagnostic criteria for PD and the rules for subclassification.

\section{Diagnostic Criteria for PD in ICD-11}

(1) General ICD-10 criteria for depression are fulfilled (duration, organic aetiology excluded). The distinction between the unipolar and bipolar branch depends on the presence of hypomanic, manic or mixed episodes prior to the current depressive episode.

(2) The ICD-10 criteria for at least 'mild depressive episode' are fulfilled (4 symptoms and at least 2 core symptoms).

(3) The first depressive episode with psychotic symptoms is labelled 'first episode' (the term 'single episode' leads to confusion). Subsequent depressive episodes with psychotic symptoms are labelled 'recurrent'. This is also the case for the bipolar branch, based on the assumption that recurrence of psychotic depressive episodes is also a marker for poor outcome in bipolar disorder. This symmetry will also facilitate comparison of first episode/recurrent PD among patients with unipolar and bipolar courses of disease. Non-psychotic depressive episodes occurring in the period between 2 psychotic depressive episodes are classified in the unipolar/bipolar diagnostic categories outside the dotted square.

(4) Psychotic symptoms (delusions or hallucinations) are present, but diagnostic criteria for schizophrenia or schizo-affective disorder are not fulfilled. However, bizarre delusions or Schneiderian first-rank symptoms persisting for less than 2 weeks during a depressive episode can still be classified as PD if the depression is the predominant state. To avoid false-positive diagnoses of PD, only beliefs that have 'delusional proportions', i.e. defy credibility, and are withheld with 'delusional intensity', i.e. not changed by rational counterarguments, are classified as delusions [25].

(5) Mood congruence is evaluated based on the same criteria as suggested for the DSM-V [110]. Mood-incongruent psychotic symptoms are less prevalent than the mood-congruent symptoms in PD $[111,112]$. Some studies have indicated that mood incongruence predicts a severer course of disease compared to mood congruence $[111,113]$, but this remains controversial [25]. It has also been proposed that PD with mood-incongruent symptoms is a less stable diagnosis than PD with mood-congruent symptoms [114]. Therefore, at least until the significance of mood congruence is clarified, it seems appropriate to stratify PD based on this quality, which also seems to be the case in the upcoming DSM-V [110]. As in the DSM-V, mood-incongruent psychotic symptoms are given precedence over mood-congruent symptoms: if both mood-congruent and mood-incongruent psychotic features are present, the episode should be labelled as 'mood-incongruent'.

(6) In addition to the evaluation of mood congruence, each diagnosis within the PD is further described according to the presence of: (a) only hallucinations; (b) only delusions; (c) hallucinations and delusions.

(7) The judgement of the severity of the syndrome as defined above should be based on a holistic evaluation of the clinical state taking both the depressive and the psychotic symptoms into account. A rating on a global severity/impairment scale seems more useful than the current rating, which is based on the mere number of symptoms. Ideally, a rating scale covering both the depressive and the psychotic dimensions of the disorder should be developed and validated for use in clinical research of PD. This scale could be constructed as a modified version of the Clinical Interview for Depression [115], which has demonstrated good clinimetric properties in the broad evaluation of affective symptomatology [116].

Note the suggested removal of stupor as a psychotic symptom in our definition of PD. In ICD-10, the only catatonic symptom classifiable under the affective disorders is depressive stupor, which has status as a psychotic symptom on a par with delusions and hallucinations [1]. However, other catatonic features like stereotypes, mannerisms or bizarre posturing can also accompany depression, but are not considered by the ICD-10. The current classification of depressive stupor as psychotic depression appears to be an unfortunate consequence of the lacking catatonia diagnosis in the ICD-10. Depression with stupor would not be labelled as PD according to the DSM-IV and the DSM-V, but, more informatively, as 'severe depression with catatonic features'. It has recently been suggested that catatonia should be classified as a distinct syndrome, separate from the diagnoses of schizophrenia and mood disorders [117]. We believe that this suggestion 
should be followed in the ICD-11. As a consequence, the catatonia diagnosis would also be applicable to the diagnosis of PD.

The vast majority of studies on PD, referenced in this paper, including the randomized controlled trials, have used the DSM-IV definition of PD as inclusion criteria. Consequently, the results of these studies are not valid for the cases of psychotic depressive episodes diagnosed according to ICD-10, where stupor is the psychotic determinant. The removal of stupor as a psychotic symptom in the ICD-11 would therefore be an advantage in research across the DSM/ICD border and increase the predictive value of future studies on PD.

Critics of the accentuated distinction between PD and non-PD outlined above would probably claim that many of the differences between the two subtypes are relative and not categorical. That might be true to some extent, but this is no different from shared phenomena between other mental disorders. For instance, symptoms of depression are common across the entire spectrum of mental disorders, but that has not precluded the nosological distinction between e.g. anxiety disorders and depression $[1,2]$. Similarly, schizophrenia and bipolar disorders share risk factors, clinical features and response to the atypical antipsychotics [118], yet they are classified under two different chapters in the diagnostic manuals $[1,2]$. Psychiatry as a field appears to have accepted that many symptoms of mental disorders are at least somewhat dimensional/continuous across the clinical syndromes [119-122]. However, we are not ready to cast the categorically defined disorders into oblivion because they aid significantly in communication among patients and health professionals, in clinical decision-making and in the definition of eligible subjects for research protocols etc. This is also reflected in the upcoming DSM-V, which appears to maintain the categorical backbone from the DSM-IV [110]. Consequently, the fact that PD and nonPD cannot be separated categorically from each other in every aspect is no different from many other diagnostic categories and should not preclude the definition of PD as a distinct syndrome.

What seems to be more important are the likely consequences of implementing the diagnostic changes suggested above. If we accept that PD fulfils the criteria for a valid psychiatric syndrome, does that merit the suggested change to the diagnostic classification? In our opinion, the short answer to this question is 'yes', simply because the advantages of doing so will outweigh the disadvantages, both for future clinical practice and for research purposes. PD is a prevalent $[3,4]$, underdiagnosed
[5] and undertreated [6] disorder. Clarifying the distinction between PD and non-PD in the diagnostic classification system would increase the focus on PD, encourage proper screening for psychosis among patients with depression and thereby decrease the high rate of missed diagnoses in current clinical practice [5]. If a larger proportion of patients suffering from PD are diagnosed properly, the overall burden of disease caused by the disorder is likely to decrease due to more targeted treatment. Furthermore, the advantages for future research appear to be several:

- increased number of eligible patients for clinical trials due to more focused diagnostics; this will create an increased incentive for researchers and pharmaceutical companies to engage in randomized controlled trials and other trials involving PD;

- facilitated research across the DSM/ICD border due to increased similarity between DSM-V and ICD-11;

- improved possibilities of investigating the significance of recurrence in BPD and across the unipolar/bipolar spectrum;

- increased power in all types of studies comparing PD with non-PD due to decreased rates of false-negative diagnoses of PD;

- enabled comparative studies of PD accompanied by only hallucinations, only delusions or both hallucinations and delusions.

We do not foresee any significant disadvantages caused by the suggested changes to the diagnostic classification. Obviously, the modifications would be followed by a period of adjustment, but even this should have limited consequences as no new concepts/nomenclature would be introduced.

\section{Conclusion}

PD fulfils the criteria for a valid psychiatric syndrome due to its distinct clinical presentation, neurobiology, heritability, prognosis and treatment response. We believe that the suggested redefinition of PD in the ICD-11 is merited and that such a revision will be of benefit to both research and clinical practice.

\section{Acknowledgement}

The authors thank Anne Katrine Leadholm for linguistic assistance. 


\section{Disclosure Statement}

S.D. Østergaard has received speaking/consultant fees from Janssen-Cilag. A.J. Rothschild has received grant support from the National Institute of Mental Health, Cyberonics, Takeda and St. Jude Medical, and has served as a consultant to Dey Pharma, Eisai Medical, GlaxoSmithKline, Eli Lilly and Pfizer. P. Uggerby has received minor honoraria from Astra-Zeneca. P. Munk-Jørgensen has received non-conditional education grants and/or minor honoraria from Astra-Zeneca, Janssen-Cilag, Servier and BristolMyers Squibb. P. Bech has received funding from, or was a speaker/member of advisory boards for, Astra-Zeneca, Lilly, $\mathrm{H}$. Lundbeck A/S and Organon. O. Mors declares no conflicts of interest.

\section{References}

1 World Health Organization: The ICD-10 Classification of Mental and Behavioural Disorders. Diagnostic Criteria for Research. Geneva, WHO, 1993.

2 American Psychiatric Association: Diagnostic and Statistical Manual of Mental Disorders, ed 4, text revision. Washington APA, 2000.

3 Gournellis R, Lykouras L: Psychotic (delusional) major depression in the elderly: a review. Curr Psychiatry Rev 2006;2:235-244.

4 Coryell W, Pfohl B, Zimmerman M: The clinical and neuroendocrine features of psychotic depression. J Nerv Ment Dis 1984;172: 521-528.

5 Rothschild AJ, Winer J, Flint AJ, Mulsant BH, Whyte EM, Heo M, Fratoni S, Gabriele M, Kasapinovic S, Meyers BS, Study of Pharmacotherapy of Psychotic Depression (STOP-PD) Collaborative Study Group: Missed diagnosis of psychotic depression at 4 academic medical centers. J Clin Psychiatry 2008;69:1293-1296.

6 Andreescu C, Mulsant BH, Peasley-Miklus C, Rothschild AJ, Flint AJ, Heo M, Caswell M, Whyte EM, Meyers BS, STOPPD Study Group: Persisting low use of antipsychotics in the treatment of major depressive disorder with psychotic features. J Clin Psychiatry 2007;68:194-200.

7 Goldberg JF, Harrow M: Consistency of remission and outcome in bipolar and unipolar mood disorders: a 10-year prospective follow-up. J Affect Disord 2004;81:123-131.

8 Park MH, Kim TS, Yim HW, Jeong SH, Lee C, Lee CU, Kim JM, Jung SW, Lee MS, Jun TY: Clinical characteristics of depressed patients with a history of suicide attempts: results from the CRESCEND study in South Korea. J Nerv Ment Dis 2010;198:748-754.

9 Vythilingam M, Chen J, Bremner JD, Mazure CM, Maciejewski PK, Nelson JC: Psychotic depression and mortality. Am J Psychiatry 2003;160:574-576.

10 Rothschild AJ: Clinical Manual for Diagnosis and Treatment of Psychotic Depression. Washington, American Psychiatric Publishing, 2009.

-11 Charney DS, Nelson JC: Delusional and nondelusional unipolar depression: further evidence for distinct subtypes. Am J Psychiatry 1981;138:328-333.
2 Glassman AH, Roose SP: Delusional depression: a distinct clinical entity? Arch Gen Psychiatry 1981;38:424-427.

13 Helms PM, Smith RE: Recurrent psychotic depression: evidence of diagnostic stability. J Affect Disord 1983;5:51-54

14 Maj M, Pirozzi R, Di Caprio EL: Major depression with mood-congruent psychotic features: a distinct diagnostic entity or a more severe subtype of depression? Acta Psychiatr Scand 1990;82:439-444.

15 Schatzberg AF, Rothschild AJ: Psychotic (delusional) major depression: should it be included as a distinct syndrome in DSM-IV? Am J Psychiatry 1992;149:733-745.

16 Widiger TA, Frances AJ, Pincus HA, Ross R, First MB, Davis WW: DSM-IV Sourcebook. Washington, APA, 1996, vol 2.

17 American Psychiatric Association: Diagnostic and Statistical Manual of Mental Disorders: DSM-III-R. Washington, APA, 1987.

18 Lichtenberg P, Belmaker RH: Subtyping major depressive disorder. Psychother Psychosom 2010;79:131-135.

19 Bech P: Struggle for subtypes in primary and secondary depression and their mode-specific treatment or healing. Psychother Psychosom 2010;79:331-338.

20 Krueger RF, Bezdjian S: Enhancing research and treatment of mental disorders with dimensional concepts: toward DSMV and ICD-11. World Psychiatry 2009;8:3-6.

21 Maj M: WPA-WHO collaborative activities 2009-2011. World Psychiatry 2009;8:129130.

22 Robins E, Guze SB: Establishment of diagnostic validity in psychiatric illness: its application to schizophrenia. Am J Psychiatry 1970;126:983-987.

23 Lykouras E, Malliaras D, Christodoulou GN, Papakostas Y, Voulgari A, Tzonou A, Stefanis C: Delusional depression: phenomenology and response to treatment. A prospective study. Acta Psychiatr Scand 1986;73: 324-329.

24 Frances A, Brown RP, Kocsis JH, Mann JJ: Psychotic depression: a separate entity? Am J Psychiatry 1981;138:831-833.

25 Maj M, Pirozzi R, Magliano L, Fiorillo A, Bartoli L: Phenomenology and prognostic significance of delusions in major depressive disorder: a 10-year prospective follow-up study. J Clin Psychiatry 2007;68:1411-1417.
26 Schatzberg AF, Posener JA, DeBattista C, Kalehzan BM, Rothschild AJ, Shear PK: Neuropsychological deficits in psychotic versus nonpsychotic major depression and no mental illness. Am J Psychiatry 2000;157: 1095-1100.

27 Gaudiano BA, Young D, Chelminski I, Zimmerman M: Depressive symptom profiles and severity patterns in outpatients with psychotic vs nonpsychotic major depression. Compr Psychiatry 2008;49:421-429.

28 Gaudiano BA, Dalrymple KL, Zimmerman M: Prevalence and clinical characteristics of psychotic versus nonpsychotic major depression in a general psychiatric outpatient clinic. Depress Anxiety 2009;26:54-64.

29 Lykouras E, Christodoulou GN, Malliaras D: Type and content of delusions in unipolar psychotic depression. J Affect Disord 1985;9: 249-252.

30 Coryell W, Leon A, Winokur G, Endicott J, Keller M, Akiskal H, Solomon D: Importance of psychotic features to longterm course in major depressive disorder. Am J Psychiatry 1996;153:483-489.

31 Rothschild AJ, Samson JA, Bond TC, Luciana MM, Schildkraut JJ, Schatzberg AF: Hypothalamic-pituitary-adrenal axis activity and 1-year outcome in depression. Biol Psychiatry 1993;34:392-400.

32 Johnson J, Horwath E, Weissman MM: The validity of major depression with psychotic features based on a community study. Arch Gen Psychiatry 1991;48:1075-1081.

33 Roose SP, Glassman AH, Walsh BT, Woodring S, Vital-Herne J: Depression, delusions, and suicide. Am J Psychiatry 1983;140: 1159-1162.

34 Munk-Jorgensen P, Lund MN, Bertelsen A: Use of ICD-10 diagnoses in Danish psychiatric hospital-based services in 2001-2007. World Psychiatry 2010;9:183-184.

- 35 Lattuada E, Serretti A, Cusin C, Gasperini M, Smeraldi E: Symptomatologic analysis of psychotic and non-psychotic depression. J Affect Disord 1999;54:183-187.

36 Bellini L, Gatti F, Gasperini M, Smeraldi E: A comparison between delusional and nondelusional depressives. J Affect Disord 1992; 25:129-138. 
37 Ohayon MM, Schatzberg AF: Prevalence of depressive episodes with psychotic features in the general population. Am J Psychiatry 2002;159:1855-1861.

- 38 Forty L, Jones L, Jones I, Cooper C, Russell E, Farmer A, McGuffin P, Craddock N: Is depression severity the sole cause of psychotic symptoms during an episode of unipolar major depression?: a study both between and within subjects. J Affect Disord 2009;114: 103-109.

- 39 Gaudiano BA, Epstein-Lubow G, Miller IW: Does the dexamethasone suppression test reliably discriminate between psychotic and nonpsychotic major depression? An exploratory analysis of potential confounds. J Nerv Ment Dis 2009; 197:395-400.

$\checkmark 40$ Holsboer F: The corticosteroid receptor hypothesis of depression. Neuropsychopharmacology 2000;23:477-501.

41 Nelson JC, Davis JM: DST studies in psychotic depression: a meta-analysis. Am J Psychiatry 1997;154:1497-1503.

-42 Posener JA, DeBattista C, Williams GH, Chmura Kraemer H, Kalehzan BM, Schatzberg AF: 24-hour monitoring of cortisol and corticotropin secretion in psychotic and nonpsychotic major depression. Arch Gen Psychiatry 2000;57:755-760.

43 Anton RF: Urinary free cortisol in psychotic depression. Biol Psychiatry 1987;22:24-34.

-44 Brown RP, Stoll PM, Stokes PE, Frances A, Sweeney J, Kocsis JH, Mann JJ: Adrenocortical hyperactivity in depression: effects of agitation, delusions, melancholia, and other illness variables. Psychiatry Res 1988;23:167178.

45 American Psychiatric Association: The dexamethasone suppression test: an overview of its current status in psychiatry. The APA Task Force on Laboratory Tests in Psychiatry. Am J Psychiatry 1987;144:12531262.

46 Rothschild AJ, Schatzberg AF, Rosenbaum AH, Stahl JB, Cole JO: The dexamethasone suppression test as a discriminator among subtypes of psychotic patients. Br J Psychiatry 1982;141:471-474.

47 DeBattista C, Belanoff J, Glass S, Khan A, Horne RL, Blasey C, Carpenter LL, Alva G: Mifepristone versus placebo in the treatment of psychosis in patients with psychotic major depression. Biol Psychiatry 2006;60:13431349.

48 Flores BH, Kenna H, Keller J, Solvason HB, Schatzberg AF: Clinical and biological effects of mifepristone treatment for psychotic depression. Neuropsychopharmacology 2006;31:628-636.

49 Belanoff JK, Flores BH, Kalezhan M, Sund B, Schatzberg AF: Rapid reversal of psychotic depression using mifepristone. J Clin Psychopharmacol 2001;21:516-521.
50 Nihalani ND, Schwartz TL: Mifepristone, a glucocorticoid antagonist for the potential treatment of psychotic major depression. Curr Opin Investig Drugs 2007;8:563-569.

51 Carroll BJ, Rubin RT: Mifepristone in psychotic depression? Biol Psychiatry 2008;63: e1, author reply e3.

52 Cubells JF, Price LH, Meyers BS, Anderson GM, Zabetian CP, Alexopoulos GS, Nelson JC, Sanacora G, Kirwin P, Carpenter L, Malison RT, Gelernter J: Genotype-controlled analysis of plasma dopamine beta-hydroxylase activity in psychotic unipolar major depression. Biol Psychiatry 2002;51:358-364.

53 Meyers BS, Alexopoulos GS, Kakuma T, Tirumalasetti F, Gabriele M, Alpert S, Bowden C, Meltzer HY: Decreased dopamine betahydroxylase activity in unipolar geriatric delusional depression. Biol Psychiatry 1999;45: 448-452.

54 Schatzberg AF, Rothschild AJ, Langlais PJ, Bird ED, Cole JO: A corticosteroid/dopamine hypothesis for psychotic depression and related states. J Psychiatr Res 1985;19: $57-64$.

55 Maj M, Starace F, Pirozzi R: A family study of DSM-III-R schizoaffective disorder, depressive type, compared with schizophrenia and psychotic and nonpsychotic major depression. Am J Psychiatry 1991;148:612-616.

56 Tsuang D, Coryell W: An 8-year follow-up of patients with DSM-III-R psychotic depression, schizoaffective disorder, and schizophrenia. Am J Psychiatry 1993;150:11821188.

57 Ruggero CJ, Kotov R, Carlson GA, Tanenberg-Karant M, Gonzalez DA, Bromet EJ: Diagnostic consistency of major depression with psychosis across 10 years. J Clin Psychiatry 2011;72:1207-1213.

58 Coryell W, Winokur G, Shea T, Maser JD, Endicott J, Akiskal HS: The long-term stability of depressive subtypes. Am J Psychiatry 1994;151:199-204.

59 Schimmelmann BG, Conus P, Edwards J, McGorry PD, Lambert M: Diagnostic stability 18 months after treatment initiation for first-episode psychosis. J Clin Psychiatry 2005;66:1239-1246.

60 Kendell RE, Malcolm DE, Adams W: The problem of detecting changes in the incidence of schizophrenia. Br J Psychiatry 1993; 162:212-218.

61 Bailar JC 3rd: Diagnostic drift in the reporting of cancer incidence. J Natl Cancer Inst 1998;90:863-864.

62 Levell NJ, Beattie CC, Shuster S, Greenberg DC: Melanoma epidemic: a midsummer night's dream? Br J Dermatol 2009;161:630634.

63 Dean K, Stevens H, Mortensen PB, Murray RM, Walsh E, Pedersen CB: Full spectrum of psychiatric outcomes among offspring with parental history of mental disorder. Arch Gen Psychiatry 2010;67:822-829.
64 Sullivan PF, Neale MC, Kendler KS: Genetic epidemiology of major depression: review and meta-analysis. Am J Psychiatry 2000; 157:1552-1562.

65 Bienvenu OJ, Davydow DS, Kendler KS: Psychiatric 'diseases' versus behavioral disorders and degree of genetic influence. Psychol Med 2011;41:33-40.

66 Bond TC, Rothschild AJ, Lerbinger J, Schatzberg AF: Delusional depression, family history, and DST response: a pilot study. Biol Psychiatry 1986;21:1239-1246.

67 Goldstein RB, Horwath E, Wickramaratne PJ, Wolk SI, Warner V, Weissman MM: Familial aggregation of delusional depression: re-examination in a recent family study. Depress Anxiety 1998;8:160-165.

68 Endicott J, Nee J, Coryell W, Keller M, Andreasen N, Croughan J: Schizoaffective, psychotic, and nonpsychotic depression: differential familial association. Compr Psychiatry 1986;27:1-13.

69 Leckman JF, Weissman MM, Prusoff BA, Caruso KA, Merikangas KR, Pauls DL, Kidd KK: Subtypes of depression: family study perspective. Arch Gen Psychiatry 1984;41: 833-838.

70 Nelson WH, Khan A, Orr WW Jr: Delusional depression: phenomenology, neuroendocrine function, and tricyclic antidepressant response. J Affect Disord 1984;6:297-306.

71 Prusoff BA, Weissman MM, Merikangas KR, Leckman JF, Harding PS: Psychiatric illness in relatives of probands with delusional depression. Psychopharmacol Bull 1984;20: 358-361.

72 Spiker DG, Kupfer DJ: Placebo response rates in psychotic and nonpsychotic depression. J Affect Disord 1988;14:21-23.

73 Spiker DG, Weiss JC, Dealy RS, Griffin SJ, Hanin I, Neil JF, Perel JM, Rossi AJ, Soloff $\mathrm{PH}$ : The pharmacological treatment of delusional depression. Am J Psychiatry 1985;142: 430-436.

74 Brown RP, Frances A, Kocsis JH, Mann JJ: Psychotic vs nonpsychotic depression: comparison of treatment response. J Nerv Ment Dis 1982;170:635-637.

75 Chan CH, Janicak PG, Davis JM, Altman E, Andriukaitis S, Hedeker D: Response of psychotic and nonpsychotic depressed patients to tricyclic antidepressants. JClin Psychiatry 1987:48:197-200

76 Kok R, Heeren T, Nolen W: Treatment of psychotic depression in the elderly compared with nonpsychotic depression. J Clin Psychopharmacol 2010;30:465-467.

77 Birkenhager TK, van den Broek WW, Mulder PG, Moleman P, Bruijn JA: Efficacy of imipramine in psychotic versus nonpsychotic depression. J Clin Psychopharmacol 2008; 28:166-170. 
-78 Narayan M, Meckler L, Nelson JC: Fluoxetine-induced delusions in psychotic depression. J Clin Psychiatry 1995;56:329.

79 Kantrowitz JT, Tampi RR: Risk of psychosis exacerbation by tricyclic antidepressants in unipolar major depressive disorder with psychotic features. J Affect Disord 2008; 106: 279-284.

$\checkmark 80$ Gaudiano BA, Miller IW, Herbert JD: The treatment of psychotic major depression: is there a role for adjunctive psychotherapy? Psychother Psychosom 2007;76:271-277.

81 Gaudiano BA, Beevers CG, Miller IW: Differential response to combined treatment in patients with psychotic versus nonpsychotic major depression. J Nerv Ment Dis 2005;193: 625-628.

82 Loo CK, Mahon M, Katalinic N, Lyndon B, Hadzi-Pavlovic D: Predictors of response to ultrabrief right unilateral electroconvulsive therapy. J Affect Disord 2011;130:192-197.

83 Petrides G, Fink M, Husain MM, Knapp RG, Rush AJ, Mueller M, Rummans TA, O'Connor KM, Rasmussen KG Jr, Bernstein HJ, Biggs M, Bailine SH, Kellner CH: ECT remission rates in psychotic versus nonpsychotic depressed patients: a report from CORE. J ECT 2001;17:244-253.

-84 Birkenhager TK, Pluijms EM, Lucius SA: ECT response in delusional versus non-delusional depressed inpatients. J Affect Disord 2003;74:191-195.

\$85 Meyers BS, Flint AJ, Rothschild AJ, Mulsant BH, Whyte EM, Peasley-Miklus C, Papademetriou E, Leon AC, Heo M, STOP-PD Group: A double-blind randomized controlled trial of olanzapine plus sertraline vs olanzapine plus placebo for psychotic depression: the study of pharmacotherapy of psychotic depression (STOP-PD). Arch Gen Psychiatry 2009;66:838-847.

-86 Wijkstra J, Burger H, van den Broek WW, Birkenhager TK, Janzing JG, Boks MP, Bruijn JA, van der Loos ML, Breteler LM, Verkes RJ, Nolen WA: Long-term response to successful acute pharmacological treatment of psychotic depression. J Affect Disord 2010;123:238-242.

87 Wijkstra J, Burger H, van den Broek WW, Birkenhager TK, Janzing JG, Boks MP, Bruijn JA, van der Loos ML, Breteler LM, Ramaekers GM, Verkes RJ, Nolen WA: Treatment of unipolar psychotic depression: a randomized, double-blind study comparing imipramine, venlafaxine, and venlafaxine plus quetiapine. Acta Psychiatr Scand 2010; 121:190-200.

88 Wijkstra J, Lijmer J, Balk F, Geddes J, Nolen WA: Pharmacological treatment for psychotic depression. Cochrane Database Syst Rev 2005;4:CD004044.

89 American Psychiatric Association: Practice guideline for the treatment of patients with major depressive disorder (third edition). 2010. http://www.psychiatryonline. com/pracGuide/PracticePDFs/PG_Depression3rdEd.pdf.
90 Bauer M, Whybrow PC, Angst J, Versiani M, Moller HJ, World Federation of Societies Biological Psychiatry Task Force on Treatment Guidelines for Unipolar Depressive Disorders: World Federation of Societies of Biological Psychiatry (WFSBP) Guidelines for Biological Treatment of Unipolar Depressive Disorders. 1. Acute and continuation treatment of major depressive disorder. World J Biol Psychiatry 2002;3:5-43.

91 Kennedy SH, Milev R, Giacobbe P, Ramasubbu R, Lam RW, Parikh SV, Patten SB, Ravindran AV, Canadian Network for Mood and Anxiety Treatments (CANMAT): Canadian Network for Mood and Anxiety Treatments (CANMAT) clinical guidelines for the management of major depressive disorder in adults. IV. Neurostimulation therapies. J Affect Disord 2009;117(suppl 1):44-53.

92 Goes FS, Sadler B, Toolan J, Zamoiski RD, Mondimore FM, Mackinnon DF, Schweizer B, Bipolar Disorder Phenome Group, Raymond Depaulo J Jr, Potash JB: Psychotic features in bipolar and unipolar depression. Bipolar Disord 2007;9:901-906.

93 Akiskal HS, Walker P, Puzantian VR, King D, Rosenthal TL, Dranon M: Bipolar outcome in the course of depressive illness: phenomenologic, familial, and pharmacologic predictors. J Affect Disord 1983;5:115-128. 94 Weissman MM, Warner V, John K, Prusoff
BA, Merikangas KR, Wickramaratne P, Gammon GD: Delusional depression and bipolar spectrum: evidence for a possible association from a family study of children. Neuropsychopharmacology 1988;1:257-264.

95 Othmer E, Desouza CM, Penick EC, Nickel EJ, Hunter EE, Othmer SC, Powell BJ, Hall SB: Indicators of mania in depressed outpatients: a retrospective analysis of data from the Kansas 1500 study. J Clin Psychiatry 2007;68:47-51.

96 Weissman MM, Prusoff BA, Merikangas KR: Is delusional depression related to bipolar disorder? Am J Psychiatry 1984;141:892893.

97 Blacker D, Faraone SV, Rosen AE, Guroff JJ, Adams P, Weissman MM, Gershon ES: Unipolar relatives in bipolar pedigrees: a search for elusive indicators of underlying bipolarity. Am J Med Genet 1996;67:445-454.

98 Mitchell PB, Wilhelm K, Parker G, Austin MP, Rutgers P, Malhi GS: The clinical features of bipolar depression: a comparison with matched major depressive disorder patients. J Clin Psychiatry 2001;62:212-216.

$\$ 99$ Forty L, Smith D, Jones L, Jones I, Caesar S, Cooper C, Fraser C, Gordon-Smith K, Hyde S, Farmer A, McGuffin P, Craddock N: Clinical differences between bipolar and unipolar depression. Br J Psychiatry 2008; 192:388389.
100 Brugue E, Colom F, Sanchez-Moreno J, Cruz N, Vieta E: Depression subtypes in bipolar I and II disorders. Psychopathology 2008;41:111-114.

101 Mitchell PB, Frankland A, Hadzi-Pavlovic D, Roberts G, Corry J, Wright A, Loo CK, Breakspear M: Comparison of depressive episodes in bipolar disorder and in major depressive disorder within bipolar disorder pedigrees. Br J Psychiatry 2011;199:303309.

102 Benazzi F: Bipolar II depression with melancholic features. Ann Clin Psychiatry 2000;12:29-33.

103 Pacchiarotti I, Valenti M, Bonnin CM, Rosa AR, Murru A, Kotzalidis GD, Nivoli AM, Sanchez-Moreno J, Vieta E, Colom F: Factors associated with initial treatment response with antidepressants in bipolar disorder. Eur Neuropsychopharmacol 2011;21: 362-369.

104 Benazzi F: Psychotic versus nonpsychotic bipolar outpatient depression. Eur Psychiatry 1999;14:458-461.

105 Mazzarini L, Colom F, Pacchiarotti I, Nivoli AM, Murru A, Bonnin CM, Cruz N, Sanchez-Moreno J, Kotzalidis GD, Girardi P, Tatarelli R, Vieta E: Psychotic versus nonpsychotic bipolar II disorder. J Affect Disord 2010;126:55-60.

106 Benazzi F: Bipolar versus unipolar psychotic outpatient depression. J Affect Disord 1999;55:63-66.

107 Nelson JC, Mazure CM: Lithium augmentation in psychotic depression refractory to combined drug treatment. Am J Psychiatry 1986;143:363-366.

108 Rothschild AJ, Samson JA, Bessette MP, Carter-Campbell JT: Efficacy of the combination of fluoxetine and perphenazine in the treatment of psychotic depression. J Clin Psychiatry 1993;54:338-342.

109 American Psychiatric Association: DSM-5 development. Proposed revision of bipolar and related disorders. 2011. http://www. dsm5.org/proposedrevision/Pages/BipolarandRelatedDisorders.aspx.

110 American Psychiatric Association: DSM-5 development. Proposed revision of major depressive disorder. 2010. http://www. dsm5.org/ProposedRevisions/Pages/proposedrevision. aspx?rid=44\#.

111 Coryell W, Tsuang MT: Major depression with mood-congruent or mood-incongruent psychotic features: outcome after 40 years. Am J Psychiatry 1985;142:479-482.

112 Winokur G, Scharfetter C, Angst J: A family study of psychotic symptomatology in schizophrenia, schizoaffective disorder unipolar depression, and bipolar disorder. Eur Arch Psychiatry Neurol Sci 1985;234: 295-298.

-113 Coryell W, Tsuang MT, McDaniel J: Psychotic features in major depression: is mood congruence important? J Affect Disord 1982;4:227-236. 
-114 Fennig S, Fennig-Naisberg S, Karant M: Mood-congruent vs mood-incongruent psychotic symptoms in affective psychotic disorders. Isr J Psychiatry Relat Sci 1996;33: 238-245.

115 Paykel ES: The clinical interview for depression: development, reliability and validity. J Affect Disord 1985;9:85-96.

116 Guidi J, Fava GA, Bech P, Paykel E: The clinical interview for depression: a comprehensive review of studies and clinimetric properties. Psychother Psychosom 2011;80: $10-27$.
117 Fink M, Shorter E, Taylor MA: Catatonia is not schizophrenia: Kraepelin's error and the need to recognize catatonia as an independent syndrome in medical nomenclature. Schizophr Bull 2010;36:314-320.

118 Moller HJ: Bipolar disorder and schizophrenia: distinct illnesses or a continuum? J Clin Psychiatry 2003;64(suppl 6):23-27.

119 Brown TA, Barlow DH: A proposal for a dimensional classification system based on the shared features of the DSM-IV anxiety and mood disorders: implications for assessment and treatment. Psychol Assess 2009;21:256-271.

120 Van Os J: 'Salience syndrome' replaces 'schizophrenia' in DSM-V and ICD-11: psychiatry's evidence-based entry into the 21 st century? Acta Psychiatr Scand 2009;120: 363-372.
121 Linscott RJ, van Os J: Systematic reviews of categorical versus continuum models in psychosis: evidence for discontinuous subpopulations underlying a psychometric continuum. Implications for DSM-V, DSMVI, and DSM-VII. Annu Rev Clin Psychol 2010;6:391-419.

122 Craddock N, Owen MJ: The Kraepelinian dichotomy - going, going ... but still not gone. Br J Psychiatry 2010;196:92-95. 